\title{
Diurnal cycle of precipitation over Fujian Province during the pre-summer rainy season in southern China
}

\author{
Wei Zhang ${ }^{1,2}$ • Anning Huang ${ }^{1}$ - Yang Zhou ${ }^{1}$ - Ben Yang ${ }^{1} \cdot$ Dexian Fang ${ }^{3}$ • \\ Lujun Zhang ${ }^{1}$ Yang $\mathrm{Wu}^{1}$
}

Received: 22 November 2015 / Accepted: 2 September 2016/Published online: 16 September 2016

(C) The Author(s) 2016. This article is published with open access at Springerlink.com

\begin{abstract}
Precipitation diurnal cycle over Fujian in the presummer rainy season has been revealed based on the hourly rain gauge data during 2009-2013. The precipitation amount (PA) over northwestern Fujian and most southeast coasts shows relatively small diurnal variability. This is in contrast to large diurnal variations in the mountainous areas. Regional differences in precipitation diurnal cycles are obviously noted among the coastal, valley, hilly, and mountainous areas. The precipitation diurnal cycles are significantly affected by the terrain elevation and distance to coast, PA and precipitation frequency (PF) show much more pronounced double diurnal peaks with the terrain elevation and distance to coast increased. However, the precipitation intensity (PI) basically shows one distinct late afternoon diurnal peak for different elevations and distances to coast. Four typical patterns of precipitation diurnal cycle are further identified by cluster analysis. The four typical PF patterns show relatively apparent morning peaks over coasts, inland mountains, and hills in addition to distinct late afternoon maxima. Low PF with weak diurnal amplitude is mainly located over the coastal areas, while high PF with strong diurnal amplitude is found over the valley, hilly, and mountainous regions. The PA exhibits a weak early morning peak and a relatively strong late afternoon peak over coastal, hilly, or mountainous areas and windward slopes but only one distinct late afternoon peak over the valley regions and leeward
\end{abstract}

Anning Huang

anhuang@nju.edu.cn

1 CMA-NJU Joint Laboratory for Climate Prediction Studies, School of Atmospheric Sciences, Nanjing University, No. 163 Xianlin Avenue, Nanjing, Jiangsu 210023, China

2 Longyan Meteorological Bureau, Fujian, China

3 Chongqing Institute of Meteorology and Science, Chongqing, China slopes. The amplitude of PA diurnal cycle is the weakest over the coastal areas but the strongest over the valley regions or leeward slopes among the four PA patterns. The four PI diurnal cycle patterns consistently show distinct afternoon peaks.

\section{Introduction}

Diurnal variation in surface and atmospheric temperature, pressure, wind fields, etc., is one of the most pronounced signals of climate and weather. It results mainly from the solar heating in surface and atmosphere (Wallace 1975; Yang and Slingo 2001; Nesbitt and Zipser 2003; Yang and Smith 2006) and often referred to as atmospheric tides (Dai and Wang 1999). Most earlier studies have also revealed diurnal variations in moist convection and cloudiness (Sui et al. 1997; Garreaud and Wallace, 1997; Yang and Slingo 2001), precipitation (Wallace 1975; Dai 2001a, b; Sorooshian et al. 2002), and atmospheric water vapor (Dai et al. 2002). These diurnal variations can affect the exchanges of energy (Bergman and Salby 1996), water (Trenberth et al. 2003), and momentum (Dai and Deser 1999) fluxes between surface and atmosphere. It is believed that the diurnal cycle of rainfall is important for the simulations of other variables in climate models (Wilson and Mitchell 1986). This is particularly true over land where the rainfall diurnal cycle is large during the warm season (Dai 2001b; Dai et al. 2007, Qian et al. 2006). As a result, revealing the diurnal cycle features of precipitation is helpful not only to understand the physical processes related to the precipitation formation (Lin et al. 2000; Trenberth et al. 2003) but also to improve the performance of weather and climate models (Dai and Trenberth 2004; DeMott et al. 2007; Liang et al. 2004; Dai 2006; Lee et al. 2007).

Many previous studies have shown that the precipitation diurnal cycle has distinct spatial and seasonal variability. The 
dominant feature of the diurnal cycle in precipitation generally shows a rainfall maximum in early morning over oceans but one peak in late afternoon over most land areas during warm season. The precipitation diurnal cycle over land is much weaker in cold season than in warm season, while the precipitation diurnal variation over oceans has relatively small seasonal changes (Yang and Slingo 2001, Nesbitt and Zipser 2003; Pinker et al. 2006). However, some studies of warm season precipitation diurnal cycle show a rainfall maximum in midnight to early morning over some particular land regions, i.e., nocturnal rainfall maxima over the eastern periphery of Tibetan Plateau (Yu et al. 2007a; Zhou et al. 2008), the southern slopes of the Himalayas (Bhatt and Nakamura 2006), and the regions east of the Rockies and the Great Plains (Dai et al. 1999c; Carbone et al. 2002; Tian et al. 2005). These nocturnal rainfall maxima result from the growth and propagation of mesoscale convective systems (MCSs) initially triggered by the diurnal heating which is strong after midnight (Carbone et al. 2002; Rickenbach 2004; Nesbitt and Zipser 2003; Jiang et al. 2006).

In recent years, precipitation diurnal cycles over southeastern China, where the climate is dominated by the East Asian monsoon, have been extensively studied based on rain gauge records and satellite observations (Yu et al. 2007a, 2007b; Li et al. 2008; Zhou et al. 2008, 2014; Yuan et al. 2010; Chen et al. 2009a, 2009b, 2010; Bao et al. 2011). Main findings are shown as follows: (1) Two comparable diurnal peaks (one in early morning and the other in late afternoon) of summer precipitation can be found over the region between the Yangtze and Yellow Rivers; (2) The eastward time delay of precipitation diurnal peak along the Yangtze River Valley in warm season is closely associated with the diurnal variation of low-level southwesterly winds; (3) Summer precipitation over southern China shows a diurnal peak in the afternoon; (4) The intraseasonal characteristics of the summer precipitation diurnal cycles is well corresponded to the shift of the East Asian monsoon rain band. Although these studies have made great progress in revealing the basic features of precipitation diurnal variation over monsoonal region, most of them used observations at the limited meteorological stations and lacked precipitation data with a higher spatial resolution. Due to the large variability of precipitation in space and time and due to the inhomogeneous spatial distribution of precipitation diurnal variation which is related to various physical processes (Chen et al. 2009b), observations from much denser network of stations are needed for revealing the detailed characteristics of the precipitation diurnal cycles in the coastal, inland, hilly, and the mountainous areas in East Asia monsoon region.

Fujian province of China with an area of $124,000 \mathrm{~km}^{2}$ is located in southern China (Fig. 1a) where the precipitation diurnal cycles vary regionally and seasonally (Li et al. 2008; Chen et al. 2009a, b) because of the complex monsoonal climate (Kan et al. 2015). The summer monsoonal rain band is firstly located over southern China during May to early June, which is called the pre-summer rainy season in southern China with the early stage of summer monsoon (Tao and Chen 1987; Ding 1992). Earlier studies have shown that the rainfall amount in the pre-summer rainy season contributes more than $30 \%$ of the annual total rainfall and about 40 $50 \%$ of the rainfall during the whole rainy season (Qiang and Yang 2008). However, the precipitation diurnal variations over Fujian in the pre-summer rainy season have not been fully addressed using hourly precipitation data series from a dense network of rain gauges. In addition, the terrain in Fujian province is complicated, such as mountainous areas in northern and central Fujian, the coastal regions in eastern Fujian, and some hilly and valley areas in western Fujian (Fig. 1b). Monsoonal climate and complex terrain in Fujian make it as a suitable region for comparing the features of precipitation diurnal cycles among the coastal, valley, hilly, and mountainous areas. In this study, we concentrate on addressing the characteristics of precipitation diurnal cycles over Fujian province during the pre-summer rainy season (May and June) in southern China based on the hourly gauge observed precipitation data during 2009-2013 from 897 stations which are almost evenly distributed across Fujian (Fig. 1b). Findings of the current study may be helpful to reveal the detailed features of the precipitation diurnal variations during the pre-summer rainy season in southern China and to provide a useful observation basis for climate model verification.

\section{Data and method}

\subsection{Data}

The data used in this study are listed as follows: (1) The hourly gauge observed precipitation data at 897 stations (Fig. 1b) over Fujian during 2009 to 2013, which is compiled and quality controlled by the Meteorological Information Center of Fujian Meteorological Bureau. The data missing rate, which is defined as ratio of the hours without observation to the total hours in the presummer rainy season over 2009-2013, ranges from 0 to $3 \%$ across all stations, indicating that the hourly gauge observed precipitation data over Fujian has very high quality and can be used to study the precipitation diurnal variation. (2)The global topographic elevation data (GTOPO30) with a horizontal grid spacing of 30 arc sec, which is available at https://lta.cr.usgs. gov/GTOPO30. (3) The ECMWF ERA-Interim reanalysis dataset during 2009 to 2013 including the $925-\mathrm{hPa}$ horizontal wind vectors and divergence with the horizontal resolution of $0.75^{\circ}$ at 00UTC, 06UTC, 12UTC, and 18 UTC, is available at http://apps.ecmwf. int/datasets/data/interim-full-daily/levtype $=$ pl. 
Fig. 1 a Location of Fujian province of China. $\mathbf{b}$ The surface elevation (shaded) and locations of the 897 rain gauge stations (white dots) in Fujian. WYM, $D M M, B P M, D Y M$, and JFM indicate Wuyi, Daimao, Boping, Daiyun, and Jiufeng mountains, respectively

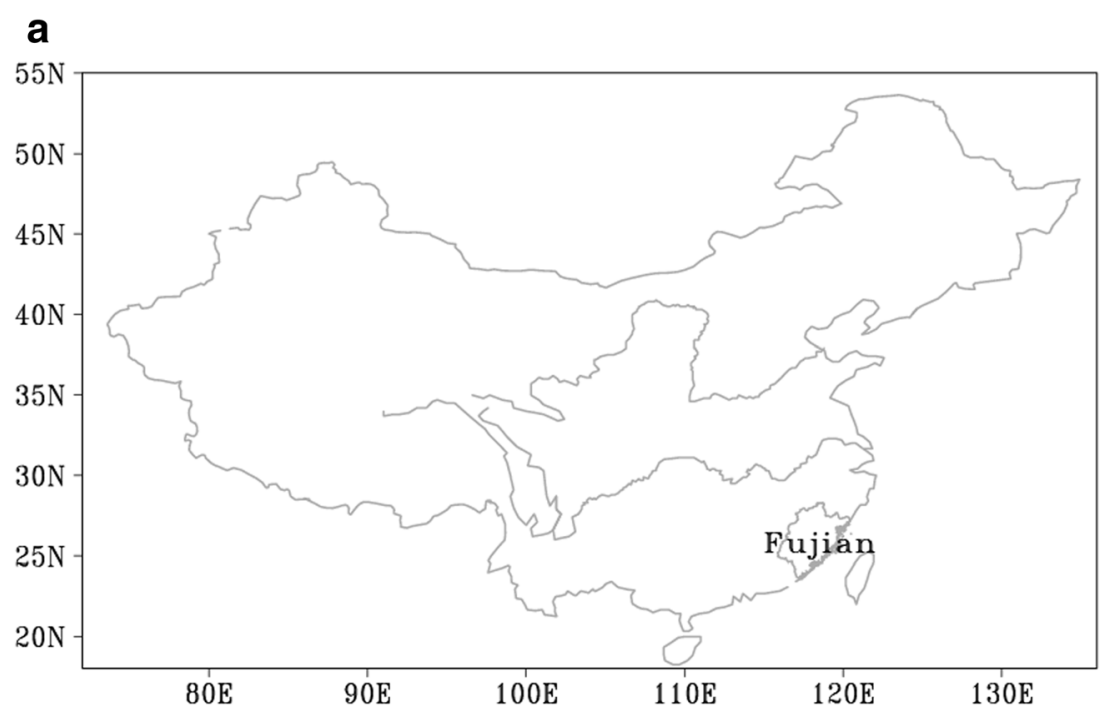

b

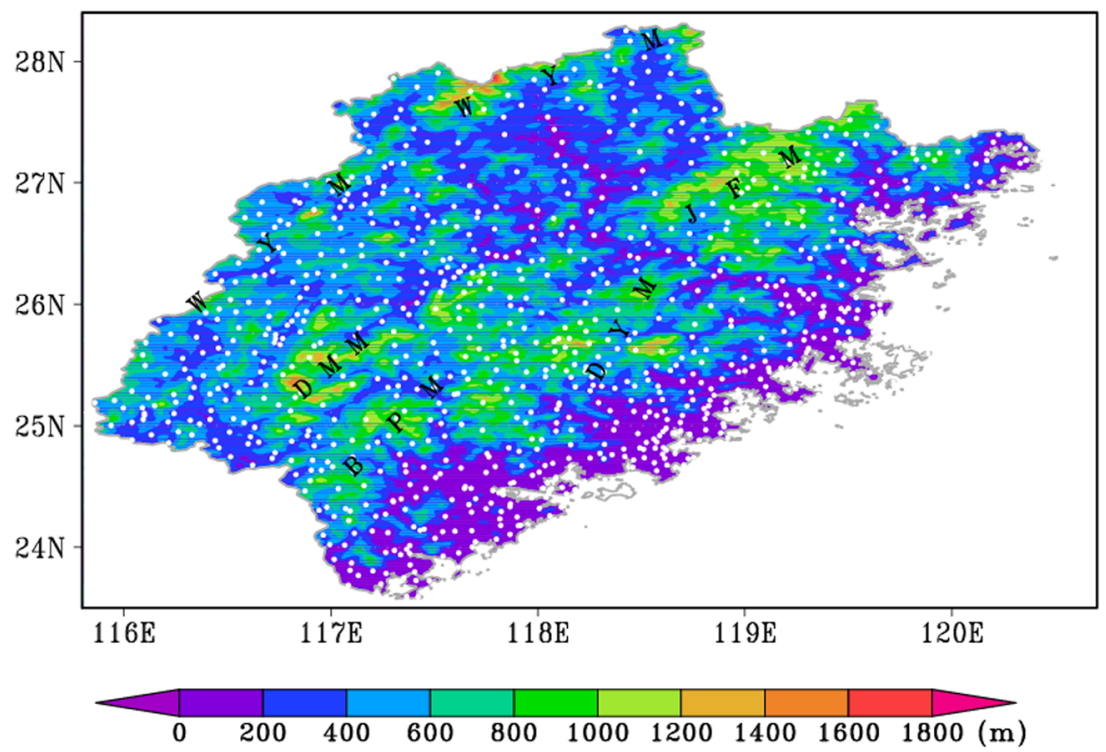

\subsection{Method}

Following Zhou et al.(2008), the precipitation amount (PA) (i.e., the accumulated precipitation divided by the number of hours during May and June), precipitation frequency (PF) (i.e., the ratio of total hours having measurable precipitation above a threshold of $0.1 \mathrm{~mm} \mathrm{~h}^{-1}$ here to the total hours during May and June), and precipitation intensity ( $\mathrm{PI}=\mathrm{PA} / \mathrm{PF}$, derived from the accumulated precipitation divided by the total precipitating hours) are computed at each hour (0000 2300 hours) in a day during the pre-summer rainy season for each station in Fujian.

To detect the representative patterns of precipitation diurnal cycles and their spatial distributions over Fujian, we firstly adopted the Fourier analysis (Yin et al. 2009) to the hourly climatic mean PA, PF, and PI at each station. The first three harmonic components are retained to represent the precipitation diurnal cycle and given by:

$\hat{y}(n)=\bar{y}+\sum_{m=1}^{3} c_{m} \cos \left(\frac{2 k \pi n}{24}-\sigma_{m}\right)+$ residual

where $m=1,2,3$ indicates the first three harmonics, and $y$ is the daily mean value. The residual is the higher order harmonics of daily variations. $c_{m}$ is the amplitude and $\sigma_{m}$ is the phase for the $m^{\text {th }}$ harmonic. $n=1,2, \ldots 24$ indicates the Beijing time (BT) expressed by the hour of a day ranging from 0000 hours to 2300 hours BT. The contribution of the $m^{\text {th }}$ harmonic to the total daily variance is explained by:

$e_{m}=\frac{0.5 c_{m}^{2}}{y_{\mathrm{var}}} \times 100 \%$ 
where $y_{\mathrm{var}}$ is the variance of the 24-h time series. $e_{m}$ indicates the contribution of the $m^{\text {th }}$ harmonic to the total daily variance and is used to reveal how much of the diurnal variations can be explained by the $m^{\text {th }}$ harmonic. The significance of each harmonic component is indicated by:

$F_{m}=\frac{0.5 c_{m}^{2} \times(24-2-1)}{\left(y_{v a r}-c_{m}^{2}\right) \times 2}$

The $F$ test, by comparing $F_{m}$ in Eq. (3) with the inverse of the $F$ distribution function with 2 and 21 degrees of freedom at significance level of $90 \%$ (Yin et al. 2009), is used to determine the significance of the harmonics.

And then, the fuzzy c mean cluster analysis (Fujibe 1999), which exhibits some advantages for obtaining a few clusters from the voluminous data and can enable partial membership of stations to clusters compared to other cluster analysis, is used to detect the typical patterns of diurnal variation over Fujian. The major patterns of precipitation diurnal cycles are constructed by the memberships and hourly series from all stations. Spatial distributions of these typical patterns are indicated by the maximal memberships at stations (Chen et al. 2009a). Meanwhile, the standard deviations of PA/PF/PI among the stations corresponding to a given cluster at each hour of day are used to show how the robustness of the cluster analysis is.

Based on the definition of de Barros Brito and Oyama (2014), the precipitation diurnal variability (PDV) is given by

$P D V=\frac{1}{n} \sqrt{\sum_{i=1}^{n}\left(\frac{x_{i}}{\bar{x}}-1\right)^{2}} \times 100 \%$

where $x$ refers to the hourly climatic mean precipitation data, $n=24$. $i=1$ corresponds to 0000 hours BT, $i=2$ corresponds to 0100 hours BT, and so on.

\section{Results}

\subsection{Spatial distribution of PA, PF and PI}

To indicate the overall features of the precipitation over Fujian during the pre-summer rainy season in southern China, Fig. 2 gives the spatial distribution of the mean PA, PF, and PI averaged over 2009-2013. Figure 2a shows that the PA decreases from the inland to the coastal regions with a strong PA center above $0.45 \mathrm{~mm} \mathrm{~h}^{-1}$ over northwestern Fujian and two large PA centers above $0.4 \mathrm{~mm} \mathrm{~h}^{-1}$ over southwestern Fujian. The locations of the PA maxima well collocate where the strong low-level convergences are (Fig. 3c). From Fig. 3a, b, the circulation patterns in May and June are quite different with more like a surface thermal-low-induced onshore flow
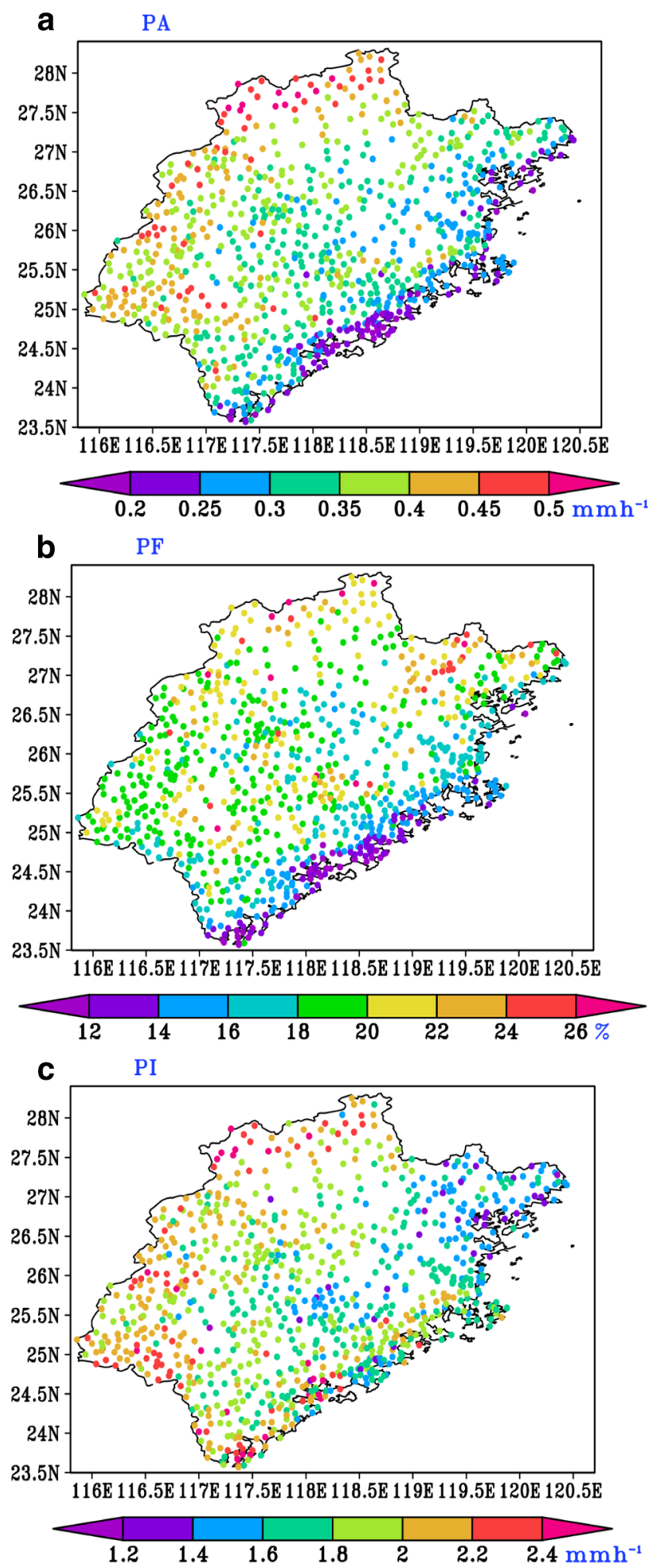

Fig. 2 Spatial distributions of the mean PA, PF, and PI over Fujian province during the pre-summer rainy season averaged over 2009 2013, respectively

towards the interior region in May while more like an established monsoon flow in June. The mean circulation patterns for May and June (Fig. 3c) clearly show that the 
Fig. 3 Spatial distributions of the ERA-Interim 925-hPa horizontal divergences (shaded, $\mathrm{s}^{-1}$ ) and wind vectors $\left(\mathrm{ms}^{-1}\right)$ during May, June, and May-June averaged over 2009-2013
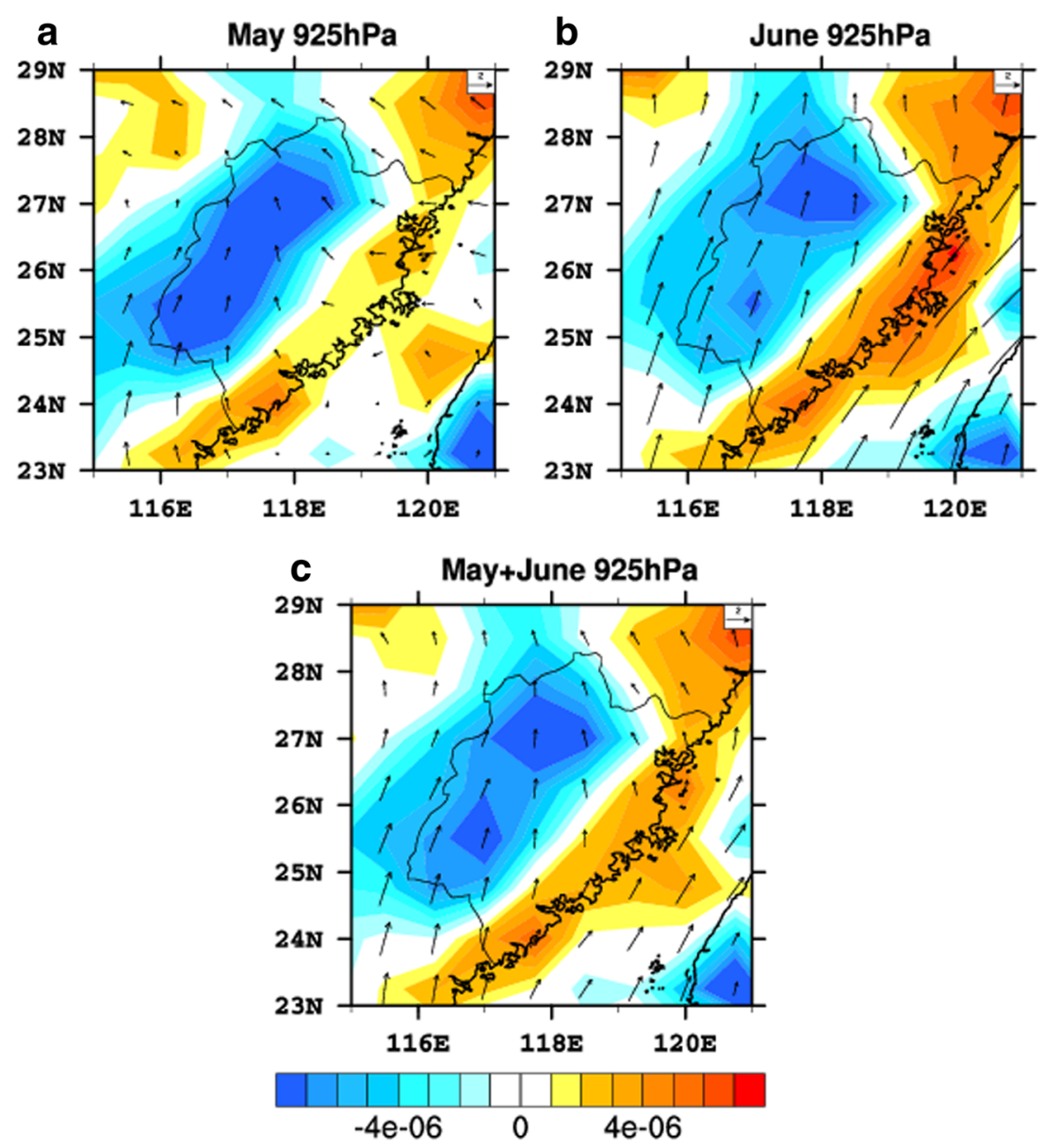

indicating strong dependence of PF and PA but weak dependence of PI on the terrain height.

\subsection{Diurnal variation of PA, PF and PI}

The spatial features of the PA diurnal variability over Fujian in the pre-summer rainy season are shown in Fig. 4. The PA shows relatively small diurnal variability over northwestern Fujian with PDV below $25 \%$ but large diurnal variability over most mountainous areas in central Fujian with PDV above $40 \%$. The PA diurnal variability is relatively strong with the PDV above $45 \%$ over the region of $118.5^{\circ}-119.5^{\circ} \mathrm{E}$ and $25.5^{\circ}-26.5^{\circ} \mathrm{N}$ where the terrain is complexly characterized by a combination of hilly, valley, mountainous, and coastal areas (Fig. 1b).

As shown in Fig. 5a-c, the strong diurnal peak centers of PA, PF, and PI are located in most hilly and mountainous areas, while weak peak centers are found over the valley and coastal areas. The PA and PI mainly show diurnal maxima in the afternoon over most Fujian except some valley regions in northwestern Fujian and coastal areas where diurnal peaks of the PA and PI generally occur in the midnight to early morning (Fig. 5d, f). The PF shows an afternoon peak over large parts of Fujian (Fig. 5e); however, the PF displays a midnight to rainy season are $0.56,0.77$, and 0.04 , respectively, 


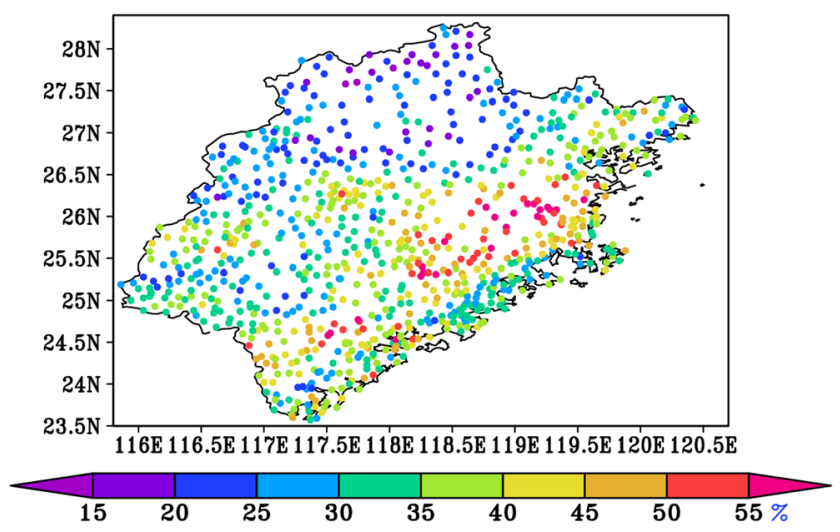

Fig. 4 Spatial distributions of the precipitation diurnal variability over Fujian province during the pre-summer rainy season over 2009-2013

early morning peak over some hilly and valley regions in northwestern Fujian and some coastal areas.
Figure 6 further gives the spatial distributions of the climatic mean PA averaged every $3 \mathrm{~h}$. The PA above 0.4 (below $0.25) \mathrm{mm} \mathrm{h}^{-1}$ over the northwestern corner of Fujian (most coastal areas in eastern Fujian) is almost steady throughout the day. The PA decreases sharply over southeastern Fujian after 2000 hours BT and then the regions with the PA below $0.3 \mathrm{~mm} \mathrm{~h}^{-1}$ expands to northwestern Fujian. In addition, the regions with the PA above $0.3 \mathrm{~mm} \mathrm{~h}^{-1}$ gradually expand from the northwest corner of Fujian southeastward to central and eastern Fujian during midnight to late afternoon. Compared with the other period in a day, the PA shows the strongest values with relatively weaker spatial variability over the entire Fujian between 1500 hours and 2000 hours BT. This PA diurnal variation well corresponds to the temporal evolution of the low-level convergences and wind vectors which are favorable for the convection formation during afternoon to early evening (Fig. 7). The solar heating in surface and atmosphere
Fig. 5 Spatial distributions of the diurnal peaks of PA, PF, and PI and their occurrence time in a day (24 h) over Fujian province in the pre-summer rainy season over 2009-2013
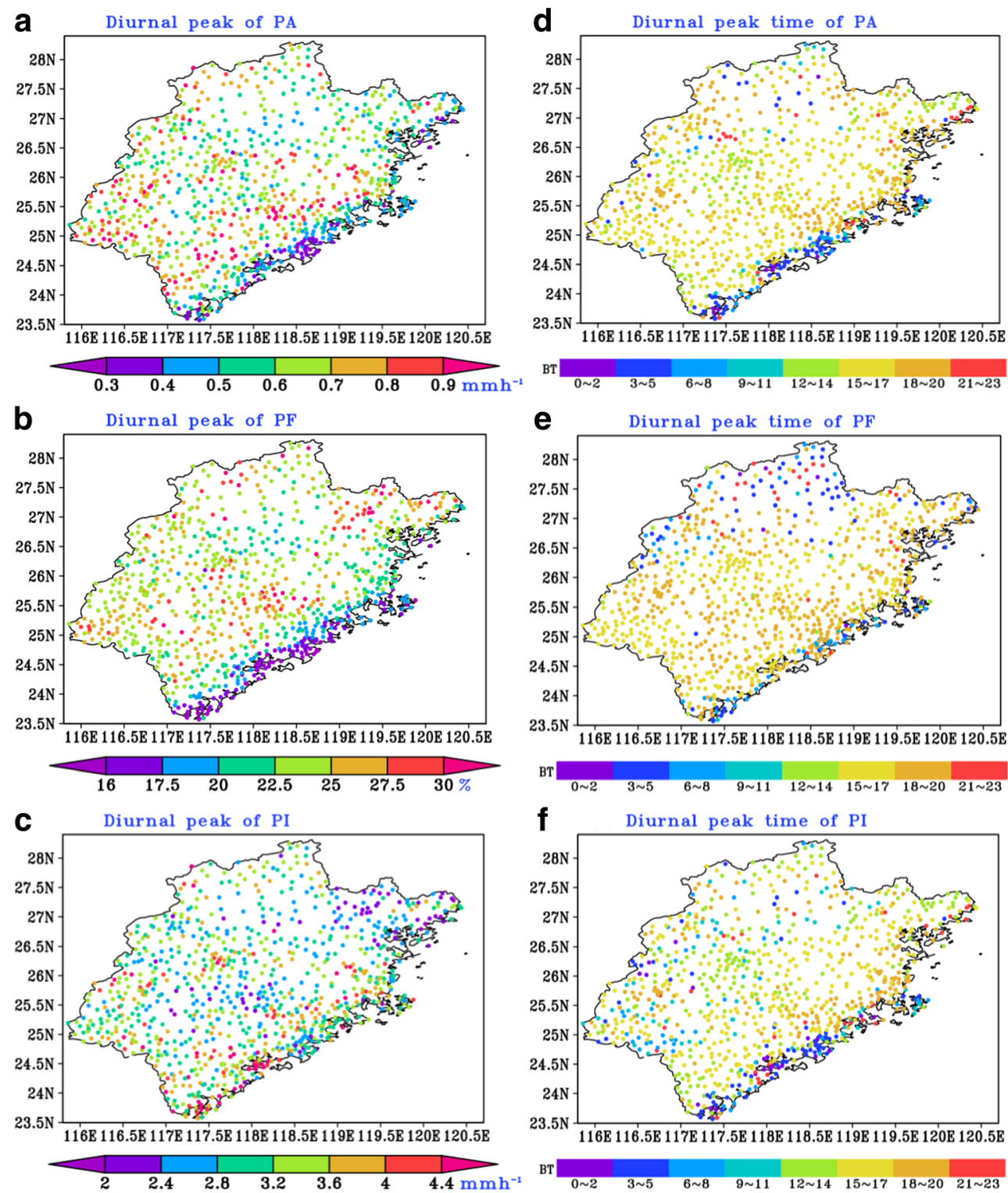

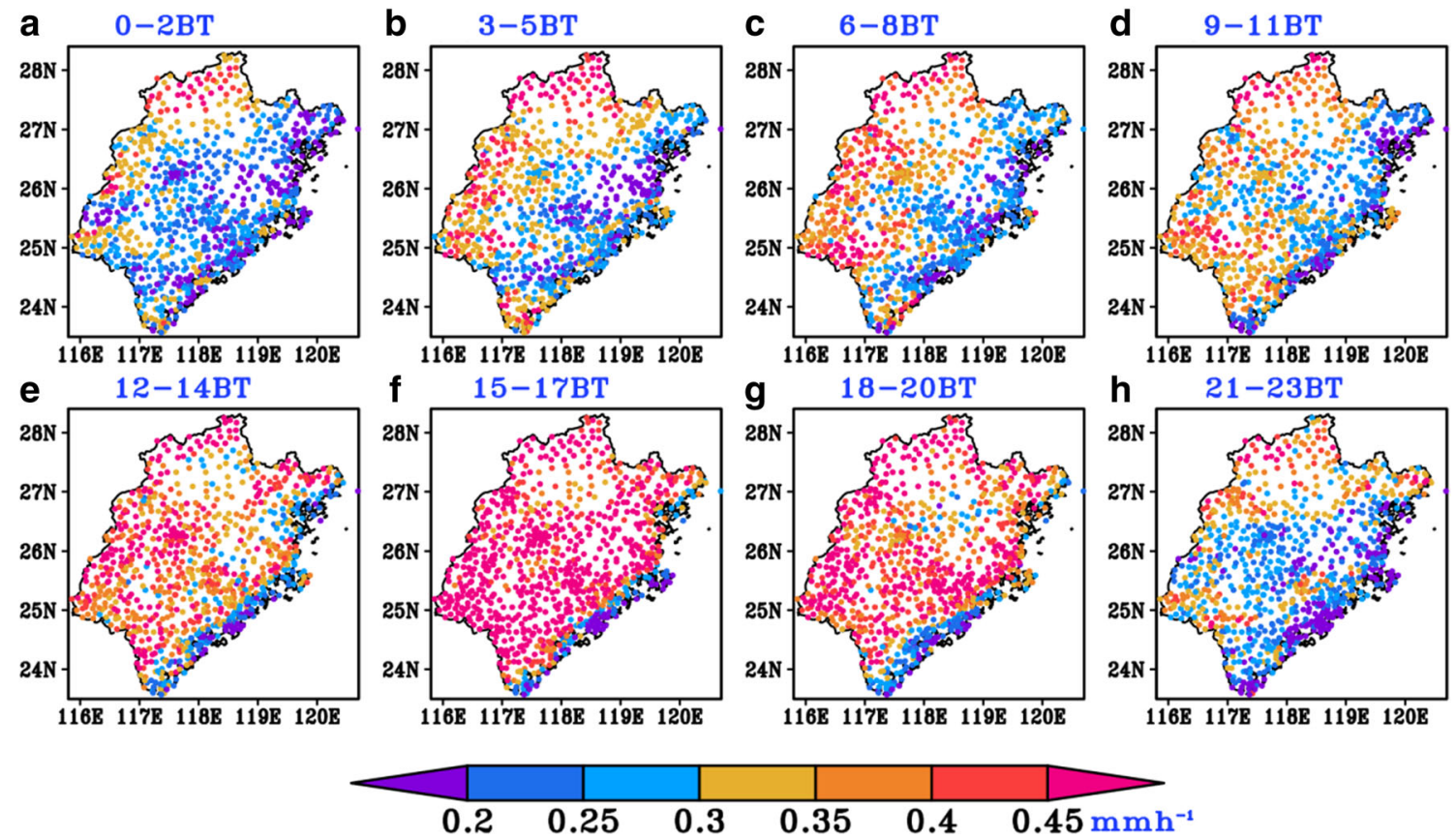

Fig. 6 Spatial distributions of the 3-hourly mean PA over Fujian province during the pre-summer rainy season averaged over 2009-2013

leads to unstable planetary boundary layer which reaches its diurnal peak and results in the maximum convergences in the late afternoon (Fig. 7b, c). As a result, the PA over most parts of Fujian peaks during afternoon to early evening (Figs. 5d, 6).
Fig. 7 Spatial distributions of the ERA-Interim 925-hPa horizontal divergences (shaded, $\mathrm{s}^{-1}$ ) and wind vectors $\left(\mathrm{ms}^{-1}\right)$ at 0200 hours, 08:00 hours, 14:00 hours, and 20:00 hours BT during the pre-summer rainy season averaged over 2009-2013
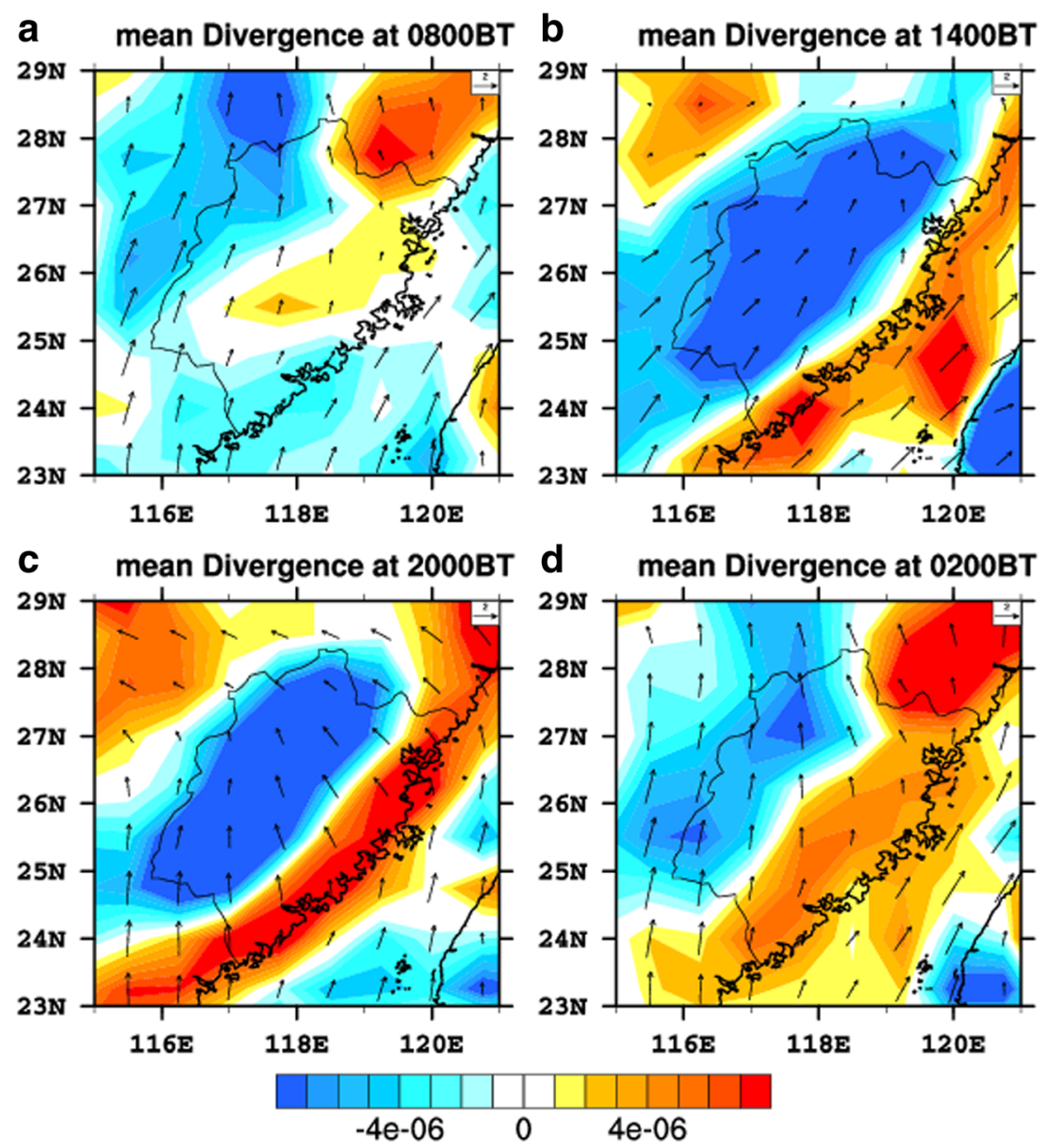


\subsection{The results of the cluster analysis}

To show the different patterns of the precipitation diurnal variation over Fujian in the pre-summer rainy season, the results of the cluster analysis are exhibited in this section. According to Yin et al. (2009), the $e_{m}$ in Eq. 2 is the percentage of the total daily variance explained by the $m^{\text {th }}$ harmonic. The higher $e_{m}$ is, the better this harmonic reflects the diurnal variability. The first three harmonic components are retained to represent the diurnal cycle of variation, and the sum of the first three $e_{m}$ can be used to reflect the significance of the harmonic analysis. We found that the stations where the contributions of at least one of the first three harmonics over the $90 \%$ significance confidence level of the $F$ test are mainly located in the regions with the first three harmonics jointly contributing more than $65 \%$ of the total daily variance. Therefore, we set the threshold of $65 \%$ for the joint contribution of the first three harmonics to pick out the stations where the total daily variance of precipitation is well explained by the first three harmonics for further cluster analysis.

As shown in Fig. 8a, the PA diurnal cycles can not be well explained by the first three harmonics at 305 stations (34\% of the total stations in Fujian marked as black dots in Fig. 8a) which are mostly located in the northwestern Fujian and coastal areas, indicating that higher harmonics $(m \geq 4)$ are needed to better capture the total daily variance of PA for these stations. The PA diurnal cycle at these stations shows three weak peaks around 0400 hours, 0800 hours, and 1700 hours BT, respectively (Fig. 8d).

The diurnal cycles of PF are mainly contributed by the first three harmonics over most parts of Fujian except 122 stations (only $14 \%$ of the total stations) mostly located along the coastal areas (Fig. 8b), where the PF has two diurnal peaks occurring around 0500 hours and 1700 hours BT (Fig. 8e). The total daily variance of PI can not be well explained by the first three harmonics at 453 stations (around $51 \%$ of the total
Fig. 8 Spatial distributions of the percentage (shadings) of the total daily variance explained by the first three harmonics for PA (a), PF (b), and PI (c) over Fujian province during the pre-summer rainy season, respectively. The black dots show the stations where all of the first three harmonics contribute to the total daily variance without passing the significant confidence level above $90 \%$ of the $F$ test. The diurnal variation of the $\mathrm{PA}(\mathbf{d}), \mathrm{PF}(\mathbf{e})$, and PI (f) regionally averaged over the stations without passing the significance confidence level over $90 \%$ of the $F$ test
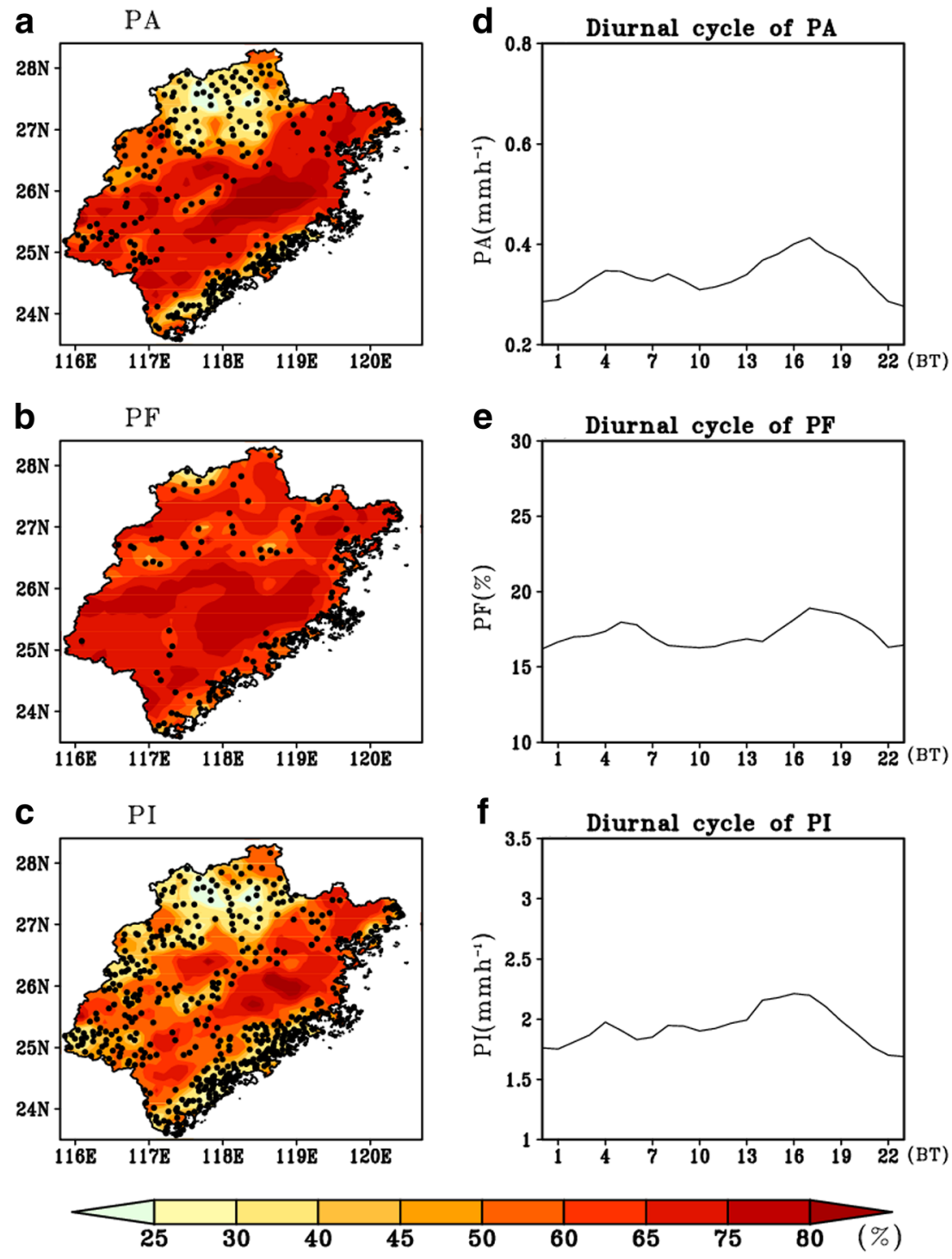
stations), which are located in most parts of Fujian except some high mountainous areas in central Fujian (Fig. 8c). The diurnal variation of PI over these stations shows more than three diurnal peaks (Fig. 8f).

Based on the fuzzy c mean cluster analysis described in Section 2.2, the typical patterns of the PA, PF, and PI diurnal cycles at the stations where the total daily variance is well explained by the first three harmonics are shown in Figs. 9, 10, and 11. The black (red) lines in Figs. 9b, 10b, and 11b show the diurnal cycles of PA, PF, and PI derived from the first three harmonics of Fourier analysis (original data), respectively. Overall, the harmonic fittings are very close to the original time series, implying that the first three harmonics of Fourier analysis can well reflect the raw data.
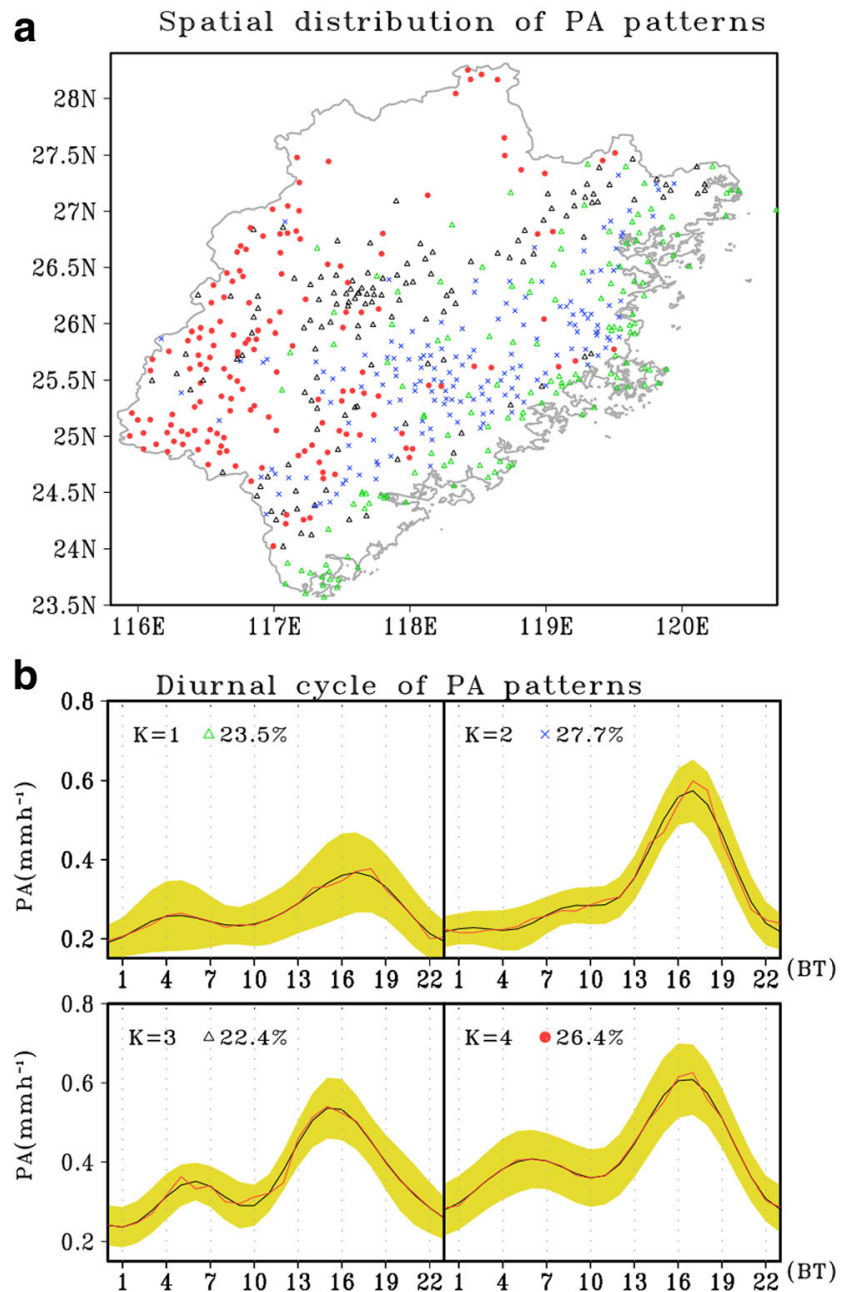

Fig. 9 a Spatial distributions of PA patterns $\mathbf{b}$ and their corresponding diurnal cycles along with the standard deviation of the PA among the stations belonging to a given cluster (shaded in yellow) over Fujian province during the pre-summer rainy season. The marks of PA patterns $\mathrm{K}$ in (a) are labeled in (b). Percentage in (b) indicates the ratio of the station numbers of each PA pattern $\mathrm{K}$ to the total stations where the total daily variance is well explained by the first three harmonics. The black (red) lines in (b) show the diurnal cycles of PA with (without) Fourier analysis
From Fig. 9a, the PA pattern $k=1$ is mainly located over the coastal regions. The PA pattern $k=2$ can be noted over the valley regions or relatively low terrain height areas east to the mountains in central Fujian. However, the PA patterns $k=3$ and 4 are located over the hilly and mountainous areas. As shown in Fig. 9a, b, the striking feature among the four typical PA patterns is that the PA diurnal variations basically decrease from west to east; this is mainly attributed to the effect of the topography on the southwest monsoonal flow (Chen et al. 2009b; Yin et al. 2011). Meanwhile, the PA pattern $k=2$ located over the valley or leeward slopes shows only one strong peak around 17:00 hours BT; this is consistent with the findings of Yin et al. (2009). However, the other three PA patterns located over coastal, hilly, or mountainous areas and windward slopes show two apparent peaks with a relatively weak one in early morning and a strong one in middle to late afternoon. In addition, the amplitude of PA diurnal variation is the weakest over the coastal areas (pattern $k=1$ ) but the strongest over valley or leeward slopes (pattern $k=2$ ) among the four PA patterns. The PA patterns $k=3$ and 4 located over

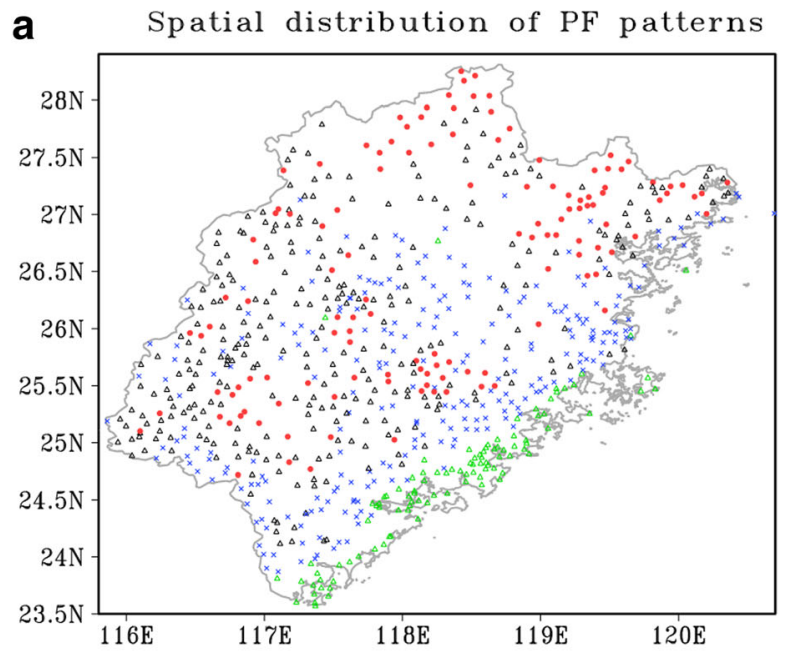

b Diurnal cycle of PF patterns
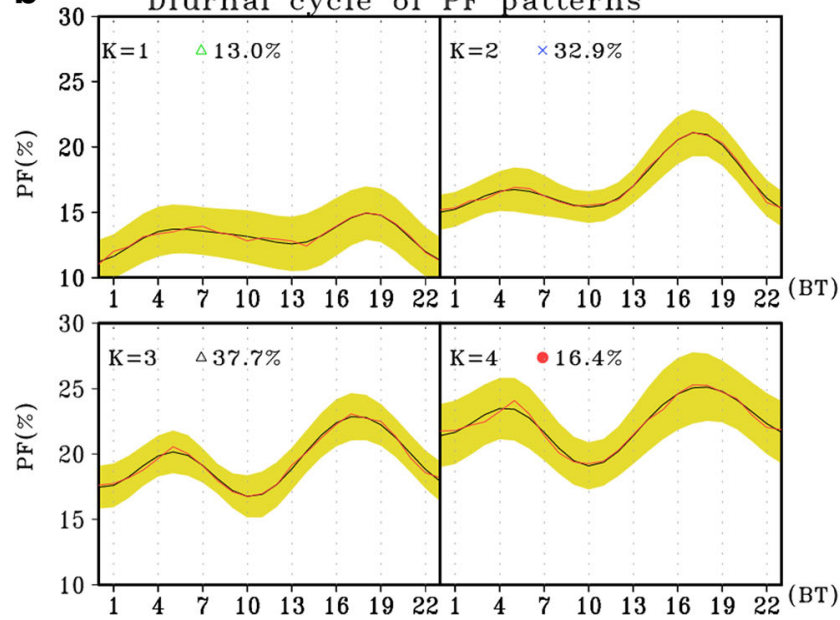

Fig. 10 Same as in Fig. 9, but for PF 
a Spatial distribution of PI patterns

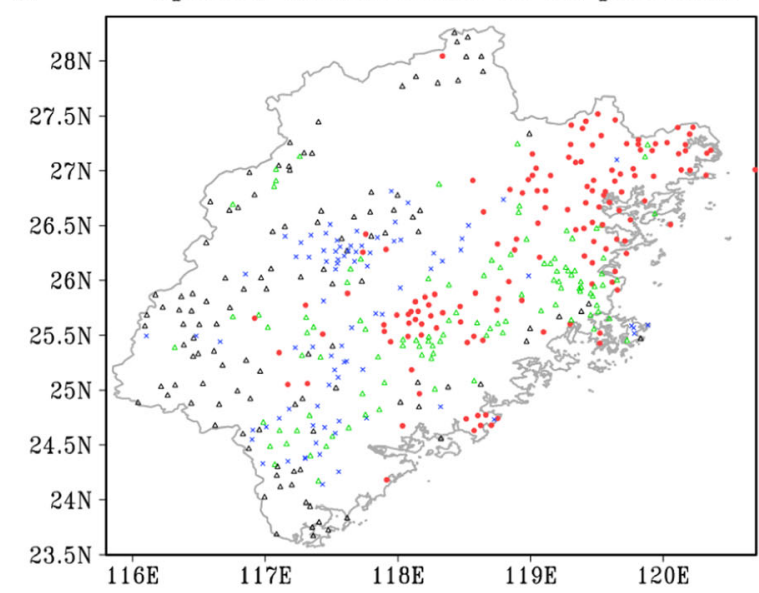

b

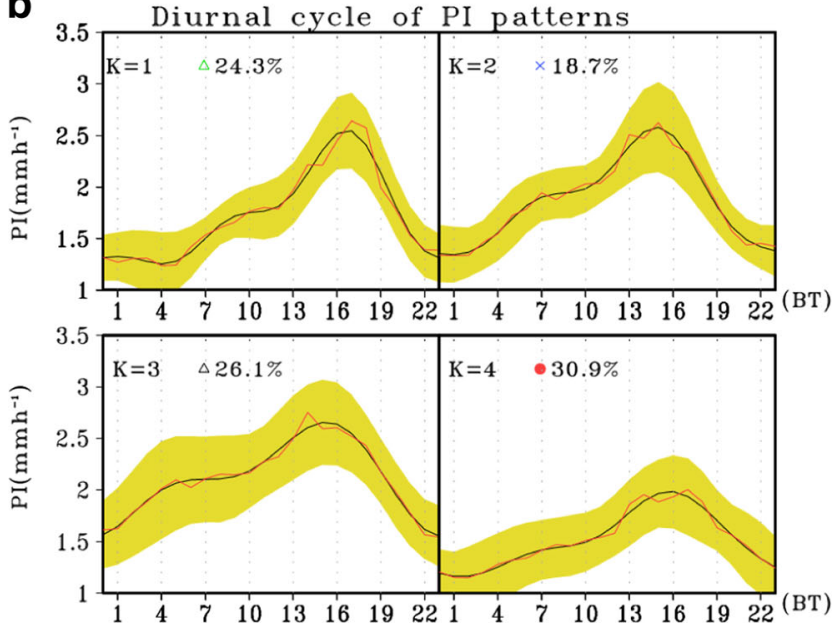

Fig. 11 Same as in Fig. 9, but for PI

hilly and mountainous areas show comparable diurnal amplitude with slight differences in the phase of diurnal cycle.

As shown in Fig. 10a, the PF diurnal variations over the coastal areas in southeastern Fujian are typically characterized by the pattern $k=1$, which shows very weak diurnal cycle (Fig. 10b). The stations with the PF pattern $k=2$ are mainly located over the valley regions or the low terrain height areas east to the mountains in the offshore areas. The PF patterns $k=3$ and 4 can be noted over the hilly and mountainous areas. The PF patterns $k=2,3$, and 4 consistently show two diurnal peaks with one in early morning and the other in late afternoon (Fig. 10b). The early morning PF peaks are relatively apparent over inland hills and mountains compared to the other regions (Fig. 10a). Low PF with weak diurnal amplitude is mainly located over the coastal regions; however, high PF with strong diurnal amplitude can be found over the valley, hilly, and mountainous regions. Meanwhile, the mean terrain height of the stations corresponding to PF patterns $k=1$ to 4 are 35,172 , 355 , and $618 \mathrm{~m}$, respectively. It is obvious that the PF in early morning enhances with the terrain height increased. This may be related to the longwave radiative cooling at night, which leads to a decrease in surface air temperature and an increase in relative humidity (Dai 2001b). In addition, the acceleration of low-level flow along the mountains at night (Fig. 7) is responsible for the upward motion of moist air and thereafter non-showery precipitation in early morning whose occurrences increase with the terrain height enhanced. Note that the decreased air temperature results in much more stable planetary boundary layer which may lead to weak PI over the high mountainous areas at night (Fig. 11b).

The stations with PF pattern $k=1$ are located over coastal regions where the solar heating in the afternoon is offset by the cooling of the air from the ocean is responsible for the relatively weaker afternoon PF peak compared with the other three PF patterns. The late afternoon PF maximum for the $\mathrm{PF}$ patterns $k=2,3$, and 4 is related to the solar heating in surface and atmosphere which can affect the static stability and thereafter lead to high PF in late afternoon (Yin et al. 2009). Previous studies using satellite-based data (Yang and Slingo 2001) showed apparent early morning PF maximum over the valley regions or areas with low elevation near to the mountains due to the mountain breeze. However, the early morning PF peak is not so obvious for the PF pattern $k=2$ over the valley regions or the low terrain height areas near to mountains. Possible reason is that mountain-valley thermal contrast is not so strong due to the relatively small spatial scale and the low elevation of mountains. The early morning PF peaks are apparent over most inland hills or mountains (PF patterns $k=3$ and 4) mainly due to the nocturnal cooling of cloud tops (Yin et al. 2009).

Different from PF and PA, the four typical patterns of the PI diurnal cycles almost show only one afternoon peak (Fig. 11b). As shown in Fig. 11a, the PI patterns $k=1$ and 2 are mainly located over the valley regions. The PI diurnal variations for patterns $k=1$ and 2 are very similar except that the occurring time of the diurnal peak in pattern $k=2$ is about $2 \mathrm{~h}$ earlier than in pattern $k=1$. However, the PI diurnal variations over the stations in the hilly or mountainous areas are characterized by the patterns $k=3$ and 4 . Most stations are mainly located in the windward slopes for the PI pattern $k=3$ but in the high mountains for the PI pattern $k=4$. From both Figs. 10 and 11, weak PI with relatively high PF tends to occur over the high mountainous areas in central Fujian.

According to cluster analysis, the features of the precipitation diurnal variations over Fujian in the pre-summer rain season vary regionally and show obvious differences among the coastal, valley, hilly, and mountainous areas. The precipitation diurnal variations varying with different elevations and distances from the coast are further given in Figs. 12 and 13. The most remarkable signal of topographic influence is the change from single peak of PA and PF over the regions with low elevation to significant double peaks with the elevation increased (Figs. 12a, b and 13a, b), while PI shows much 
clearer single late afternoon peak with the elevation increased (Figs. 12c, 13c). Equally noted is the influence of distance to coast (Figs. 12d-f and 13d-f). Much clearer signal of the distance to coast influence is single peak of PA and PF gradually changing to double peaks with the distance to coast increased (Figs. 12d-e and $13 \mathrm{~d}-\mathrm{e}$ ). It is also noted that the late afternoon peaks of PA and PF over the regions located east of mountains with the distance of $50-100 \mathrm{~km}$ from the coast are much stronger than those over the other regions (Fig. $13 \mathrm{~d}, \mathrm{e}$ ). This may be related to the low-level convergences and more water vapor transport resulting from the afternoon prevailing sea breeze against the mountains (Yu et al. 2009).

\section{Concluding remarks}

In this study, characteristics of the precipitation diurnal variations over Fujian of China during the pre-summer rainy season have been analyzed based on the hourly data from 897 stations during 2009-2013. In addition, the typical patterns of diurnal variation over Fujian in the pre-summer rainy season are also identified based on the fuzzy c mean cluster analysis (Fujibe 1999). The major findings are summarized as follows:

The spatial patterns of PF and PA over Fujian in the presummer rainy season strongly depend on the topography. The PA shows relatively small diurnal variability over northwestern Fujian and most southeast coasts but much larger diurnal variability over most mountainous areas in central to eastern Fujian. The PA and PF mainly show a diurnal peak in afternoon over most parts of Fujian but an early morning peak over some valley and hilly regions in northwestern Fujian and coastal areas in southeastern Fujian. Whereas the afternoon PI diurnal maxima are pronounced over most parts of Fujian except northwestern Fujian where the PF peaks during midnight to early morning.

Four typical patterns (coastal, valley, mountain, and hilly types) of precipitation diurnal variation over Fujian in the presummer rainy season are further identified by the fuzzy c mean
Fig. 12 The elevation-time (a-c) and distance to coast-time (d-f) cross section of the hourly mean $\mathrm{PA}, \mathrm{PF}$, and PI at the 897 stations over Fujian province during the pre-summer rainy season averaged over 2009-2013

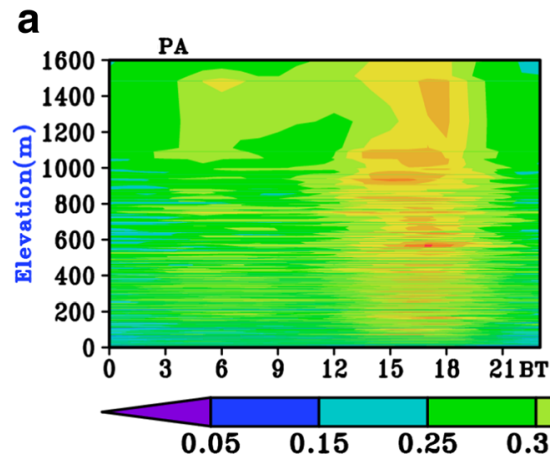

d

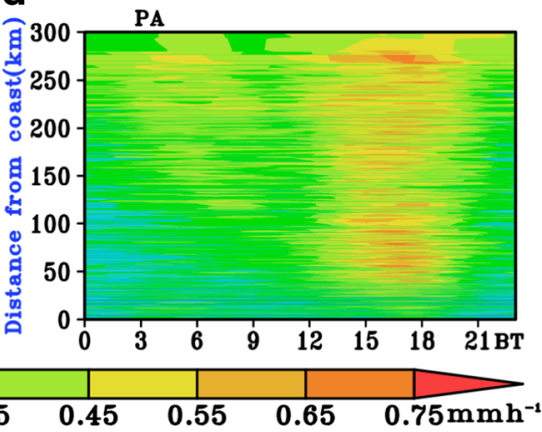

b

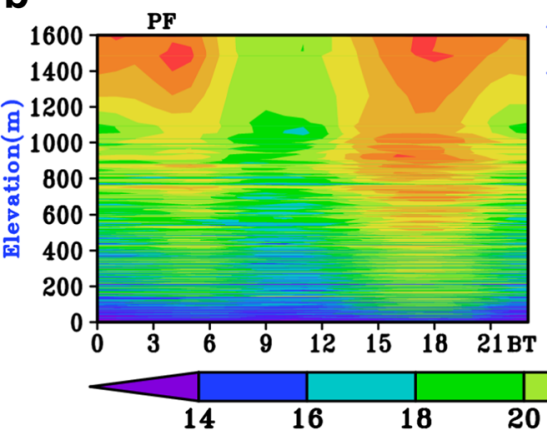

e

$\widehat{\sigma}_{300}$

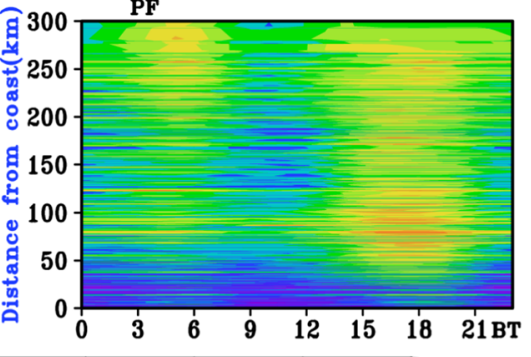

C

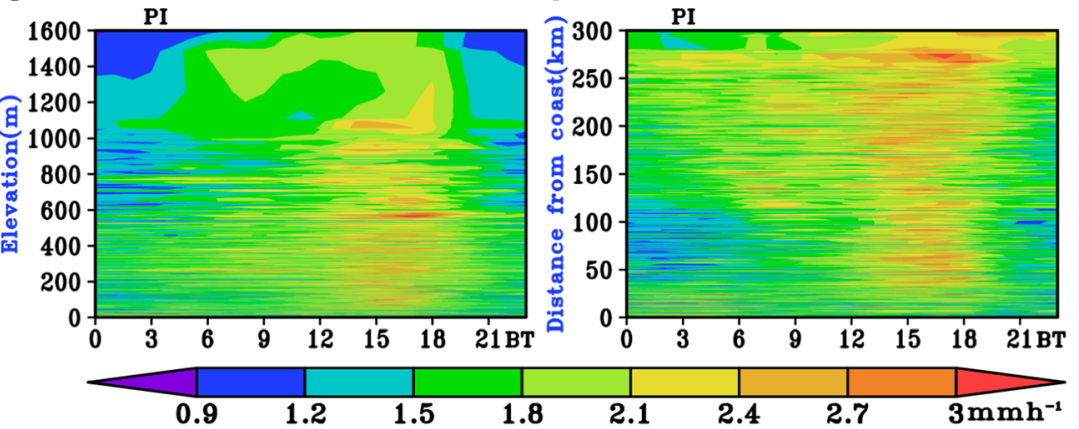


Fig. 13 The diurnal cycles of the mean PA, PF, and PI for the period of 2009-2013 regionally averaged over the stations in terms of elevation $(\mathbf{a}-\mathbf{c})$ and distance to coast (d-f) over Fujian during the pre-summer rainy season
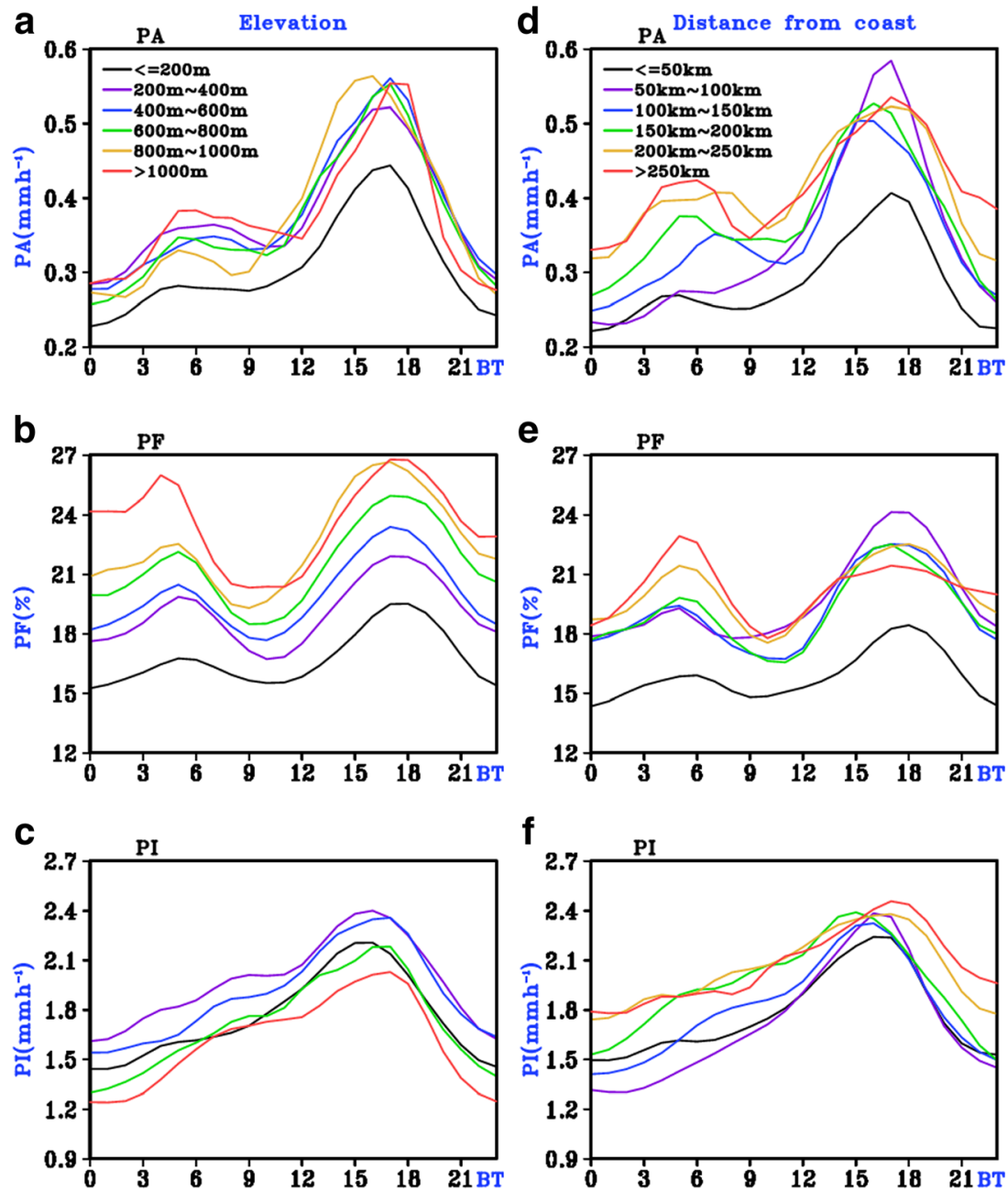

cluster analysis. The typical patterns of precipitation diurnal variation over Fujian in the pre-summer rainy season are primarily dependent on the topography and monsoonal flows. The four typical PF patterns consistently show two diurnal peaks with one in early morning and the other in late afternoon. Relatively apparent PF early morning peaks can be seen over the coasts, inland mountains, and hills. Low PF with weak diurnal amplitude is mainly located over the coastal regions in southeastern Fujian, while high PF with strong diurnal amplitude is found over the valley, hilly, and mountainous regions. The PA diurnal variations for each pattern basically decrease from west to east due to the topographic effect. The PA diurnal variation over the valley or leeward slopes shows only one strong late afternoon peak around 1700 hours BT. The PA diurnal cycle over the coastal, hilly, or mountainous areas and windward slopes shows a weak early morning peak and a relatively strong afternoon peak. Among the four PA patterns, the amplitude of PA diurnal variation is the weakest over the coastal areas but the strongest over the valley or leeward slopes. Compared to PF and PA, the four typical PI diurnal cycle patterns consistently show distinct afternoon peaks.
The rainfall diurnal cycles over Fujian in the pre-summer rainy season are significantly affected by the terrain elevation and distance to coast. With the terrain elevation and distance to coast increased, PA and PF show much more pronounced double diurnal peaks. However, for different elevations and distances from the coast, the PI basically shows one distinct late afternoon diurnal peak.

Overall, based on the rain gauge data with high spatialtemporal resolution, the results indicates large regional differences in precipitation diurnal cycles among the coastal, valley, hilly, and mountainous areas during pre-summer rainy season. The PF and PA show apparent early morning peaks in addition to distinct late afternoon maxima. These results are supportive of earlier findings related to the regional features of precipitation diurnal variations over southern China during the presummer rainy season. Yu et al. (2007b) pointed out that the early morning peak is attributed to the long duration rain events associated with the stratiform clouds but the late afternoon peak is resulted from the short-duration rain events related to the convective clouds due to solar heating. Some previous studies have indicated that the precipitation diurnal variation may be correlated with the local effects, such as 
complex topography (Johnson et al. 1993), land-sea breeze circulations (Yang and Slingo 2001), and mountain-valley breezes (Ohsawa et al. 2001) and their interaction with the prevailing winds, or the long life cycle of mesoscale convective systems (Nesbitt and Zipser 2003). The diurnal cycles of rainfall over Fujian in southern China during the pre-summer rainy season show large regional differences due to the complex terrain and activity of the East Asian summer monsoon (Chen et al. 2009b). Because of the limitation of the available data, it is difficult to illustrate clearly the diurnal evolution of the physical processes related to the precipitation diurnal cycles over Fujian during the pre-summer rainy season. The underlying physical mechanisms, such as the diurnal evolution of dynamical and thermal forcings related to precipitation diurnal cycles are complicated and remain as open questions. These issues need to be further addressed using more observational data and high resolution numerical simulations in the future.

Acknowledgments This work was supported by the National Natural Science Foundation of China under Grants 41175086 and 41575052, the Jiangsu Collaborative Innovation Center for Climate Change and the Special Fund for the Meteorological Scientific Research of Public Sector (Grant GYHY201306032). We are grateful to the editor and two anonymous reviewers for their careful review and constructive comments.

Open Access This article is distributed under the terms of the Creative Commons Attribution 4.0 International License (http:// creativecommons.org/licenses/by/4.0/), which permits unrestricted use, distribution, and reproduction in any medium, provided you give appropriate credit to the original author(s) and the source, provide a link to the Creative Commons license, and indicate if changes were made.

\section{References}

Bao X, Zhang F, Sun J (2011) Diurnal variations of warm-season precipitation east of the Tibetan plateau over China. Mon Weather Rev 139:2790-2810

Bergman JW, Salby ML (1996) Diurnal variations of cloud cover and their relationship to climatological conditions. J Clim 9:2802-2820

Bhatt BC, Nakamura K (2006) A climatological-dynamical analysis associated with precipitation around the southern part of the Himalayas. J Geophy Res 111:D02115. doi:10.1029/2005 JD006197

Carbone RE, Tuttle JD, Ahijevych DA, Trier SB (2002) Inferences of predictability associated with warm season precipitation episodes. J Atmos Sci 59:2033-2056

Chen G, Sha W, Iwasaki T (2009a) Diurnal variation of precipitation over southeastern China: spatial distribution and its seasonality. J Geophys Res 114:D13103. doi:10.1029/2008JD011103

Chen G, Sha W, andIwasaki T (2009b) Diurnal variation of precipitation over southeastern China: 2. Impact of the diurnal monsoon variability. J Geophys Res 114:D21105. doi:10.1029/2009JD012181

Dai A (2001a) Global precipitation and thunderstorm frequencies. Part I: seasonal and interannual variations. J Clim 14:1092-1111

Dai A (2001b) Global precipitation and thunderstorm frequencies. Part II: diurnal variations. J Clim 14:1112-1128
Dai A (2006) Precipitation characteristics in eighteen coupled climate models. J Clim 19:4605-4630

Dai A, Deser C (1999) Diurnal and semidiurnal variations in global surface wind and divergence fields. J Geophys Res 104:31109-31125

Dai A, Trenberth KE (2004) The diurnal cycle and its depiction in the community climate system model. J Clim 17:930-951

Dai A, Wang J (1999) Diurnal and semidiurnal tides in global surface pressure fields. J Atmos Sci 56:3874-3891

Dai A, Giorgi F, Trenberth KE (1999) Observed and model simulated diurnal cycles of precipitation over the contiguous United States. J Geophys Res 104:6377-6402

Dai A, Wang J, Ware RH, Van Hove T (2002) Diurnal variation in water vapor over North America and its implications for sampling errors in radiosonde humidity. J Geophys Res 107:409. doi:10.1029/2001JD000642

Dai A, Lin X, Hsu K (2007) The frequency, intensity, and diurnal cycle of precipitation in surface and satellite observations over low- and midlatitudes. Climate Dyn 29:727-744

de Barros Brito SS, Oyama MD (2014) Daily Cycle of Precipitation over the Northern Coast of Brazil. J Appl Meteorol Climatol 53(11): 2481-2502

DeMott CA, Randall DA, Khairoutdinov M (2007) Convective precipitation variability as a tool for general circulation model analysis. J Clim 20:91-112

Ding Y (1992) Summer monsoon rainfalls in China. J Meteorol Soc Jpn 70(1B):373-396

Fujibe F (1999) Diurnal variation in the frequency of heavy precipitation in Japan. J Meteorol Soc Jpn 77(6):1137-1149

Garreaud RD, Wallace JM (1997) The diurnal march of convective cloudiness over the Americas. Mon Weather Rev 125:3157-3171

Jiang X, Lau NC, Klein SA (2006) Role of eastward propagating convection systems in the diurnal cycle and seasonal mean of summertime rainfall over the U.S. Great Plains. Geophys Res Lett 33: L19809. doi:10.1029/2006GL027022

Johnson RH, Wang Z, Bresch JF (1993) Heat and moisture budgets over China during the early summer monsoon. J Meteorol Soc Jpn 71(1): $137-152$

Kan M, Huang A, Zhao Y, Zhou Y, Yang B, and Wu H (2015) Evaluation of the summer precipitation over China simulated by BCC CSM model with different horizontal resolutions during the recent half century. J. Geophys. Res. Atmos., 120, doi:10.1002/2015JD023131.

Lee MI et al. (2007) An analysis of the warm-season diurnal cycle over the continental United States and northern Mexico in general circulation models. J Hydrometeor 8:344-366

Li J, Yu R, Zhou T (2008) Seasonal variation of the diurnal cycle of rainfall in southern contiguous China. J Clim 21(22):6036-6043. doi:10.1175/2008JCLI2188.1

Liang X, Li L, Dai A, andKunkel KE (2004) Region climate model simulation of summer precipitation diurnal cycle over the United States. Geophys Res Lett 31:L2420. doi:10.1029/2004GL021054

Lin X, Randall DA, Fowler LD (2000) Diurnal variability of the hydrologic cycle and radiative fluxes: comparisons between observations and a GCM. J Clim 3(23):4159-4179

Nesbitt SW, Zipser EJ (2003) The diurnal cycle of rainfall and convective intensity according to three years of TRMM measurements. J Clim 16:1456-1475

Ohsawa T, Ueda H, Hayashi T, Watanabe A, Matsumoto J (2001) Diurnal variations of convective activity and rainfall in tropical Asia. J Meteor Soc Japan 79:333-352

Pinker RT, Zhao Y, Akoshile C, Janowiak J, Arkin P (2006) Diurnal and seasonal variability of rainfall in the sub-Sahel as seen from observations, satellites and a numerical model. Geophys Res Lett 33: L07806. doi:10.1029/2005GL025192

Qian T, Dai A, Trenberth KE, Oleson KW (2006) Simulation of global land surface conditions from 1948 to 2004. Part I: forcing data and evaluation. J. Hydrometeor. 7:953-975 
Qiang X, Yang X (2008) Onset and end of the first rainy season in South China (in Chinese). Chinese JGeophys 51(5):1333-1345

Rickenbach TM (2004) Nocturnal cloud systems and the diurnal variation of clouds and rainfall in southwestern Amazonia. Mon Weather Rev 132:1201-1219

Sorooshian S, Gao X, Hsu K, Maddox RA, Hong Y, Gupta HV, Imam B (2002) Diurnal variability of tropical rainfall retrieved from combined GOES and TRMM satellite information. J Clim 15:983-1001

Sui CH, Lau KM, Takayabu YN, andShort DA (1997) Diurnal variations in tropical oceanic cumulus convection during TOGACOARE. J Atmos Sci 54:639-655

Tao S, Chen L (1987) A review of recent research on the east Asian summer monsoon in China. In: Chang CP, Krishnamurti TN (eds) Monsoon meteorology. Oxford Univ. Press, New York, pp. 60-92

Tian B, Held IM, Lau NC, Soden BJ (2005) Diurnal cycle of summertime deep convection over North America: a satellite perspective. J Geophys Res 110:D08108. doi:10.1029/2004JD005275

Trenberth KE, Dai A, Rasmussen RM, Parsons DB (2003) The changing character of precipitation. Bull. Amer Meteor Soc 84:1205-1217

Wallace JM (1975) Diurnal variations in precipitation and thunderstorm frequency over the conterminous United States. Mon Weather Rev 103:406-419

Wilson CA, Mitchell JFB (1986) Diurnal variation and cloud in a general circulation model. Quart J Roy Meteor Soc 112:347-369

Yang GY, Slingo J (2001) The diurnal cycle in the tropics. Mon Weather Rev 129:784-801
Yang S, Smith EA (2006) Mechanisms for diurnal variability of global tropical rainfall observed from TRMM. J Clim 19:5190-5226

Yin SQ, Chen D, Xie Y (2009) Diurnal variations of precipitation during the warm season over China. Int J Climatol 29(8):1154-1170. doi: $10.1002 /$ joc. 1758

Yin S, Li W, Chen D, Jeong J-H, Guo W(2011) Diurnal variations of summer precipitation in the Beijing area and the possible effect of topography and urbanization. Adv Atmos Sci 28(4):725-734

Yu R, Zhou T, Xiong A, Zhu Y, Li J (2007a) Diurnal variations of summer precipitation over contiguous China. Geophys Res Lett 34:L01704. doi:10.1029/2006GL028129

Yu R, Xu Y, Zhou T, Li J (2007b) Relation between rainfall duration and diurnal variation in the warm season precipitation over central eastern China. Geophys Res Lett 34:L13703. doi:10.1029/2007GL030315

Yu R, Li J, Chen H (2009) Diurnal variation of surface wind over central eastern China. Clim Dyn 33:1089-1097

Yuan W, Yu R, Chen H, Li J, Zhang M (2010) Subseasonal characteristics of diurnal variation in summer monsoon rainfall over central eastern China. J Clim 23:6684-6695

Zhou T, Yu R, Chen H, Dai A, Yang P (2008) Summer precipitation frequency, intensity, and diurnal cycle over China: a comparison of satellite data with rain gauge observations. J Clim 21:39974010

Zhuo H, Zhao P, Zhou T (2014) Diurnal cycle of summer rainfall in Shandong of eastern China. Int J Climatol 34(3):742-750 